\title{
Editorial
}

\section{Acupuntura na Faculdade de Medicina da USP}

\section{Acupuncture at "Faculdade de Medicina da USP"}

\author{
André Wan Wen Tsai ${ }^{1}$, Wu Tu Hsing ${ }^{2}$
}

\begin{abstract}
A acupuntura é o ramo da Medicina Tradicional Chinesa (MTC) que utiliza a estimulação de pontos anatômicos localizados no corpo para promover a saúde ou prevenir certas doenças. Acredita-se que tal prática foi desenvolvida há mais de 4.500 anos na China, onde posteriormente foram também desenvolvidos os conhecimentos sobre fitoterapia e moxabustão. Desde então, a acupuntura tem sido praticada em toda a China, divulgada também para outros países como o Japão e a Coréia, e aos poucos vem conquistando adeptos no mundo ocidental. Foi a partir de 1972, após a visita do então presidente norte americano Richard Nixon à China, que a acupuntura teve maior divulgação no ocidente. Isso porque durante sua estada no país, o jornalista americano da revista New York Times, James Reston, que acompanhava o presidente, reportou sua experiência pessoal ao receber analgesia pós operatória (pós apendicectomia) com acupuntura.

Com o intuito de explicar o funcionamento da acupntura e comprovar, de fato, sua eficácia, o número de trabalhos científicos vem aumentando de modo considerável. Em 1997, o National Institute of Health (NIH) dos Estados Unidos divulgou um consenso sobre a acupuntura, publicado um ano após (NIH Consensus). Segundo esse documento, a acupuntura é eficaz no tratamento de náuseas e vômitos em pacientes que recebem quimioterapia ou que estão no pós operatório. Também é recomendada para a analgesia pós procedimentos odontológicos em adultos. A acupuntura apresenta ainda benefícios complementares no tratamento do acidente vascular encefálico, cefaléia, dismenorréia, epicondilite lateral, fibromialgia, dor miofascial, osteoartrose, síndrome do túnel do carpo, lombalgia e asma, além da drogadição.

No Brasil, a acupuntura tem crescido tanto no meio popular como no acadêmico, principalmente nos últimos 50 anos, sendo reconhecida pelo Conselho Federal de Medicina como especialidade médica desde 1995. Neste mesmo ano iniciou o Curso de Especialização em Acupuntura no Instituto de Ortopedia e Traumatologia do HCFMUSP oferecida aos médicos como pós graduação de extensão universitária.

Diante do interesse crescente entre os alunos da Casa de Arnaldo, em 2002 e 2003 iniciaram, respectivamente, as atividades da Liga de Acupuntura e do Curso Optativo, sendo este, o curso mais procurado entre as matérias optativas da graduação com uma média de 45 alunos do terceiro ano por semestre.

Para coordenar melhor as atividades em acupuntura no HC foi criado em 2006 o Centro de Acupuntura do Instituto de Ortopedia e Traumatologia do HCFMUSP, onde abriga um corpo docente de mais 20 médicos, todos graduados pela USP e provenientes de especialidades diferentes, como Fisiatria, Ortopedia, Neurologia Clínica, Neurocirurgia, Clínica Médica, Dermatologia, Pediatria, Reumatologia, Patologia e Cirurgia, proporcionado aos alunos e pacientes uma abordagem multidisciplinar que o doente crônico requer.

A acupuntura no HCFMUSP não parou de crescer. Em 2007 iniciou o programa de Residência Médica em Acupuntura no Hospital das Clínicas e que oferece estágios dentro do HCFMUSP, como também em outros hospitais conveniados como ICESP (Instituto do Câncer do Estado de São Paulo), HU (Hospital Universitário - USP), Chang Gung Memorial Hospital (Taiwan) e Taipei City Hospital (Taiwan).

Hoje, além dos atendimentos ambulatoriais de terças e quintas à tarde pelo Centro de Acupuntura do IOT-HCFMUSP, há ainda outros polos de atendimento de acupuntura:

$>$ Instituto da Criança (ICr): responsável - Dra. Marialda Höfling de Pádua Dias. Quintas à tarde, Disciplina de Dor e Cuidados Paliativos;

> Ambulatório da Dor (PAMB): responsável - Dr. Hong Jin Pai. Sextas de manhã, Disciplina da Neurologia.

$>$ Ambulatório de Geriatria (PAMB): responsável - Prof. Yolanda Garcia. Quintas de manhãs. Disciplina da Geriatria.

Obviamente, em se tratando de uma Faculdade como a nossa, não poderia faltar a parte de pesquisa clínica que estão sendo desenvolvidos nos ambulatórios já citados, bem como teses de doutoramento em andamento, contribuída em parte à parceria com Harvard Medical School.
\end{abstract}

1. Médico ortopedista e acupunturista da turma 82 da FMUSP, Coordenador do curso de Medicina Tradicional Chinesa do Centro de Acupuntura do IOT/HCFMUSP, Diretor do Colégio Médico de Acupuntura do Estado de São Paulo (CMAESP).

2. Médico fisiatra e acupunturista da turma 67 da FMUSP, Diretor do Centro de Acupuntura do IOT/HCFMUSP, Coordenador da Liga e do Curso Optativa de Acupuntura da FMUSP, Supervisor do Programa de Residência Médica em Acupuntura do HCFMUSP, Professor da Disciplina de Telemedicina da FMUSP.

Endereço para correspondência: tsai.andre@gmail.com; wu@fmusp.org.br 